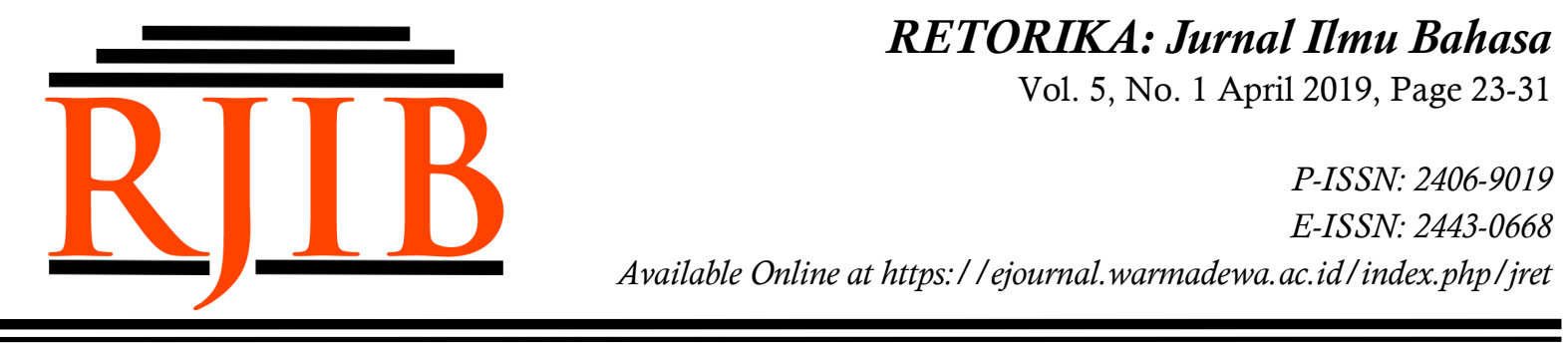

\title{
Taboo Words in 21 Jump Street Movie
}

\author{
Desak Gede Yulia Kusumaningsih
}

Universitas Warmadewa, Denpasar, Bali-Indonesia

sakdeyulia@yahoo.com

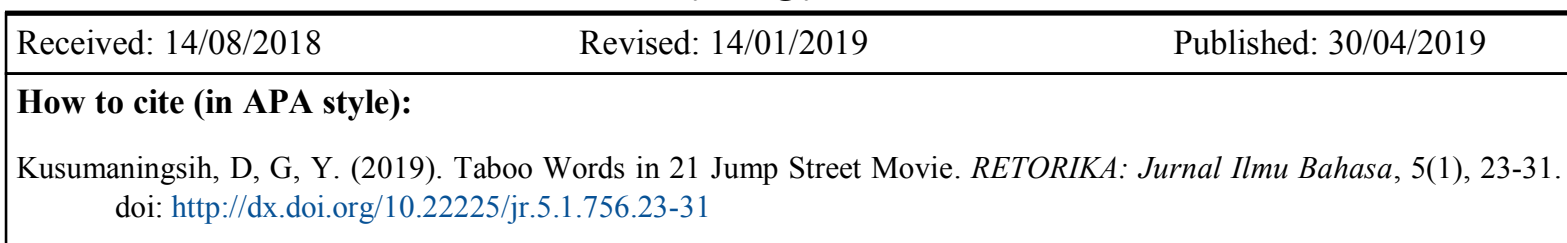

\begin{abstract}
The aim of this research is to classify the kinds, functions of taboo words, and the factors which cause the characters use the taboo words in the movie. Data were analyzed by using taboo words theory by Michael Swan and factors underlying cursing theory by Timothy Jay. The data were taken from 21 Jump Street movie. In this research, library research method is used in analyzing taboo words in 21 Jump Street movie. The procedures of the research are: first, the movie is watched and the topics for the paper are found. Second, the theory in the books and internet are found. Third, the movie script is searched and the taboo words are classified. The last, the taboo words in 21 Jump Street movie are discussed and analyzed by using Michael Swan and Timothy Jay theories. Based on the result of the analysis, there are three kinds of taboo word that found in 21 Jump Street movie: (1) religion, (2) private parts of the body and sexual activity, and (3) lavatory. Private parts of the body and sexual activity has the biggest number of occurrence, while the smallest number of taboo words' kind is religion. There are six functions of using taboo words that I found in the movie. They are: insult, exclamation of annoyance, surprised question, exclamation of surprise, emphasize an emotion, and miscellaneous. The most appeared function is to insult and the smallest is as a surprised question. Furthermore, the reason of the characters in 21 Jump Street movie to used taboo words are based on the situation and context. On the other hand, there are three reasons of using taboo words which found in the movie, such as psychological condition, social class, and ethnic group. Psychological condition has the biggest number of occurrence, while the smallest is social class.
\end{abstract}

Keywords: Movies; sociolinguistics; taboo words.

\section{INTRODUCTION}

In daily life, language has an important role. Without language, people may not be able to carry out their life. Even the disabled people such as the deaf people still have their own language for communication, it is a sign language. It is a means of humans to communicate with others. In a daily life, people should have abilities of reading and listening to receive information and speaking, and writing to give information. As a means of communication, language has several functions. Generally, people use language to communicate their intention to others. Specifically, language is used by people to convey messages, idea and thoughts or to send information in order to make the conversation activities run smoothly. In other words, language is functioned as a means to share information such as recent news, interesting activities and gossip. In addition, the language can be used as a distinguishing feature from a social group because each social group has a different language and also as a manifestation of the unity of a group. In terms of psychology, language can be used as a means to understand ourselves and others. Language also serves as a means of self-development. Language is the specialized sound signaling system which seems to be genetically programmed to develop in humans. It is usually known as the psychology of communication (Aitchison, 1992). 
From the social side, the language has a function as a means of social integration and adaptation. Language has an important role in social control. Language can serve a communication controller so that the people involved in the communication are able to understand each other. As an example of social control, the language is used to introduce the idea which is used to make rules or laws in order to reach the regular social condition. Therefore, every person has their own way to choose the language variation which can confirm one's identity. Some people may prefer to use language that has a strong impact when they are sad or angry. For instance, people sometimes use certain kind of words that are considered as a bad language which is actually inappropriate to use. One of the ways to express their feeling is by producing taboo words. People usually produce taboo words to swear because they are the strongest way to express their dissatisfaction.

Taboo is one research of Sociolinguistics that has relation with culture and society. Taboo describes something prohibited, forbidden or interdiction thing because it is not proper with the religion and custom in the society. Taboo words are prohibited to be uttered because they are improper and viewed as bad and rude language. Taboo is the prohibition of avoidance in any society of behavior believed to be harmful to its members in that it would cause them anxiety, embarrassment, or shame (Wardhaugh, 2010).

The usage of taboo words also can be found in movies. In movies, taboo words always bring out social culture, education and somebody's identity. To analyze taboo words, 21 Jump Street movie by Phil Lord and Chris Miller has chosen as research material. It is interesting to analyze this movie, because it has interesting and entertaining story. There are also many of taboo words used by the characters (actor or actress) that can be analyzed, for example:

Jenko : There's not a nice way to put it. You're a fucking nerd. And, you know, she's, I don't know, she's hot. Look at her. Look at her! Look at her! (21 Jump Street, 02.10)

The word fucking in the example above refers to taboo words because this word relates to sexual activity. In this case Jenko teases Scmidt that he does not deserve to take Melodie to the prom night because Schmidt is a nerd while Melodie is a sexy girl who must be paired with a handsome man. The word fucking is used by Jenko, because this word is a powerful word which can disturb people who hears it. Jenko wants to insult Schmidt. More over the social class is the reason that makes the character use the word fucking, for instance, when people is angry with something or somebody, they tend to use taboo words to express what they feel.

Through this research, there are a lot of taboo words which are used by many characters in conversation that are forbidden. Nevertheless, it makes the conversation looks more colorful, friendly, and convenient. Besides, the kinds, function, and the reason that makes the characters use them can be analyzed and classified. Psychological, physiological, and neurological studies confirm the emotional quality of taboo expressions; forbidden words are more arousing, more shocking, more memorable, and more evocative than all other language stimuli (Burridge, 2014).

\section{Taboo Words}

Taboo, is a proscription on behavior for a specific community in a specific context. In every culture, there are both taboo acts (things that you're not supposed to do) and taboo words (things that you're not supposed to say). While some taboo acts have corresponding taboo words, others don't (Fairman, 2009). Taboo subjects include: body functions about sex and excretion, private parts of the body, illness and death; words believed to be blasphemy; income, salary, age of ladies, etc. Societies in different countries share this point of view, especially in English-speaking countries (Gao, 2013). Taboo word as behavior that is believed to be supernaturally forbidden or regarded as immoral or improper. It deals with behavior which is prohibited or inhibited in an apparently irrational manner and taboo word is associated with things which are not said, and in particular with words and expressions which are not used (Trudgill, 2000). According to Radcliffe-Brown, taboo word means simply 'to forbid', 'forbidden', and can be applied to any sort of prohibition. So something that forbid to say in front of public and it is not suitable to use (Allan \& Burridge, 2006). Based on the definition above, taboo word is a bad word to use in front of public, because taboo word has its own rule which is not legal to use by people. In formal situation, the standard language is used. Standard language is the variety of language 
which has the highest status in a community or nation and which is usually based on the speech and writing of educated native speakers of the language/the formal language is also used in specific situations such as meeting, public speaking, seminars, and others. Whereas, in the informal situation, the language used is the non-standard language. Non-standard language is any speech variety used by a social group, community or nation that is different in its pronunciation, grammar and lexicon from the standard form of language. Non-standard language or style does not follow the rules of standard language like using of taboo word.

\section{Kinds of Taboo Words}

Many languages have words which are considered dangerous, holy, magic or shocking, and which are only used in certain situations or by certain people. For instance, in some African tribes the names of dead chiefs must not be said; in many cultures, words associated with religious beliefs are used only on religious occasions, or only by priests. Words of this kind can be called 'taboo words'. English has three main groups of taboo words and expressions (Swan, 1995):

\section{Religion}

A number of words connected with the Christian religion (e.g. the names Christ, God) are considered holy by some people. These people prefer to use such words only in formal and respectful contexts, and they may be upset or shocked by their 'careless' use. For example: damn (condemn to hell (rare in literal sense; mainly used as swear word)), blast (strike with divine punishment (rare in literal sense; mainly used as swear word)), hell, God, Jesus, Christ.

\section{Private Parts of the Body and Sexual Activity}

Certain words relating to sexual activity and the associated parts of the body (e.g. fuck, balls) are regarded as shocking by many people. Thirty or forty years ago some of these words could not be printed or broadcast, and they are still comparatively unusual in public speech and writing. In polite or formal language these words are generally avoided, or replaced by other words and expressions (e.g. make love or have sexual intercourse, testicles). Example of taboo words in parts of the body category: ass (bottom, buttocks, anus), asshole (anus), balls(testicles), cock (penis), dick (penis), prick (penis), tits (breasts), cunt (woman's sex organs), twat (woman's sex organs). Example of taboo words in sexual activity category: fuck (have sex (with)), jerk off (masturbate (have sex with oneself)), bugger (have anal intercourse with a person or animal; person who does so (rare in literal sense)), come (reach a sexual climax (orgasm)), sod (homosexual (abbreviation of sodomite; rare in literal sense)), bitch (female dog; earlier used for 'immoral' woman), whore (prostitute), bastard (child of unmarried parents).

\section{Lavatory}

Some words referring to the elimination of bodily wastes (what one does in the lavatory), and the associated parts of the body, are also regarded as 'dirty' or shocking (e.g. piss, shit). They are often replaced by more 'polite' words and expressions with the same meaning (e.g. urinate, defecate) or by substitutes (e.g. go to the lavatory, wash one hands). For example: piss (urine; urinate), shit (excrement; defecate), crap (excrement; defecate), fart (let digestive gas out from the anus).

\section{Function of Taboo Words}

The following list shows some of the most common expressions used in swearing; they are grouped according to meaning (Swan, 1995).

- Exclamation of Annoyance

- Exclamation of Surprise

- Surprised Question

- Insult (noun)

- Insult (imperative verb + object)

- Insulting request to go away

- Expression of unconcern (= 'I don't care')

- Violent refusal/rejection/defiance

- Intensifying adjective/adverb (used to emphasize an emotion)

\section{- Miscellaneous}

\section{The Reason of Using Taboo Words}

There are some reasons underlying the use of taboo words. They are psychological condition, social class, and ethnic group.

\section{Psychological Condition}

One's identity is realized through the use of language; one's approach to or style of cursing is part of identity realization. From a psychological perspective, each person acquires a language and an identity through a collection of behaviors, habits, traits, abilities, and mental processes; these factors shape his or her cursing. Psychological factors are influenced by neurological processes and socio 
cultural constraints (Jay, 2000). Psychological is the main factor that made swear word is use. At the psychological level, one's personality, child rearing, and genetic makeup provide a range of restrictions on the likelihood of cursing. Cursing is acquired early, as a function of the learning environment and psychological state of mind (Jay, 2000).

\section{Social Class}

Different social groups use different linguistic varieties, and as experienced members of a speech community we have learnt to classify speakers accordingly (Trudgill, 2000: 23). Speakers at the top of the social scale (cone) speak Standard English with very regional variation. Any variation that is apparent will usually occur between two (or more) equally standard forms, but the further down the social scale we go, the greater regional variation will show (Trudgill, 2000: 30 ). It may be fair to say that many regular swear word speakers come from anarchic or lower-class backgrounds, and that they swear primarily as a means of distancing themselves from mainstream society and affirming their position as a member of a particular social group (Gray, n.d.).

\section{Ethnic Group}

In daily activity, especially in the United State, there are two dominant ethnics that very prominent between white and black English. Actually, people said to be ethnic is to be black. There are differences between spoken by many Whites and many African Americans in the United States of America such that Americans can, and do, and assign people with some confidence to one of the two ethnic groups solely on the basis of their language. Although the stereotypes of black or white speech which listeners work with provide them with a correct identification most of the time, the diagnostic differences are entirely the result of learned behavior (Trudgill, 2000). In this case, wherever African people live they are called Black English that different with Standard English. The connection between language and ethnic group may be a simple one of habitual association, reinforced by social barriers between the groups (Trudgill, 2000).

Research about taboo words already been done before by pratama (2016), his research concerning to Translating taboo words in subtitling especially translating them into Indonesian is quite difficult since most of the Indonesian people are not used to uttering taboo or offensive words publicly. He found
The functions of those taboo words are to express sympathy, surprise, disappointment, disbelief, fear, annoyance, metaphorical interpretation, reaction to mishap, to emphasize the associated item, function as adjectival intensifier, name-calling, anaphoric use of epithet, oath, curse, unfriendly suggestion, and four of them show non-swearing word or dysphemism (Pratama, 2016).

The gap of research is concerning in taboo, especially when we talk about kinds of taboo words, such as religion, private parts of the body and sexual activity, and lavatory, function and reason of using taboo words, because of that, this research analyze and discuss about the usage of taboo words in 21 Jump Street movie.

\section{METHOD}

The method of collecting data in this research used observation method. There are some steps of collecting data. First, 21 Jump Street movie is identified by watching. Also, the script of the movie is read, then words that include taboo words categorize are marked. Second, find out the kinds, functions, and the reason of using taboo words in the movie. The obtained data are collected and noted. The method analysis data in this research used qualitative method. Although this research employed qualitative method, the writer also used quantitative method to support the interpretation of data. Therefore, by providing statistical work in the form of percentage, the writer could easily describe the phenomenon that she wanted to investigate by giving fixed percentages to make a clear explanation. The method in presenting data in this research used informal and formal method. Informal method used to describe the analysis result of two problems in this research by using ordinary words in order to give the clear understanding. The model of formal method in this research used tables to show clearly the frequency of the occurrence of kinds, function, and reason of taboo words uttered by the characters in 21 Jump Street movie.

\section{III.RESULT AND DISCUSSION}

\section{Kinds of Taboo Words in 21 Jump Street Movie}

English has three main groups of taboo words and expressions: (1) religion, (2) sexual activity and private parts of the body, and (3) lavatory. From the analysis process, the total data collected in this research are 27 data and 
are displayed in Table 1. The table shows the frequency of the occurrence of kinds of taboo words uttered by the characters in 21 Jump
Street movie. The result are various and they will be displayed in the following table.

Table 1

Frequency of Occurrence of Kinds of Taboo Words in 21 Jump Street Movie

\begin{tabular}{|c|c|c|c|c|c|}
\hline \multirow{2}{*}{ No. } & \multirow{2}{*}{ Taboo Words } & \multicolumn{3}{|c|}{ Kinds } & \multirow{2}{*}{ Total } \\
\hline & & REG & PRIV\&SEX & LAV & \\
\hline 1. & Goddamn & $\sqrt{ }$ & & & \\
\hline 2. & Damn & $\sqrt{ }$ & & & \\
\hline 3. & Fuck & & $\sqrt{ }$ & & \\
\hline 4. & Suck my dick & & $\sqrt{ }$ & & \\
\hline 5. & Motherfucker & & $\sqrt{ }$ & & \\
\hline 6. & Suck somebody's dick & & $\sqrt{ }$ & & \\
\hline 7. & Titties & & $\sqrt{ }$ & & \\
\hline 8. & Fucking & & $\sqrt{ }$ & & \\
\hline 9. & Shit & & & $\sqrt{ }$ & \\
\hline 10. & Balls & & $\sqrt{ }$ & & \\
\hline 11. & Ass & & $\sqrt{ }$ & & \\
\hline 12. & Bullshit & & & $\sqrt{ }$ & \\
\hline 13. & Bitches & & $\sqrt{ }$ & & \\
\hline 14. & Dick & & $\sqrt{ }$ & & \\
\hline 15. & Motherfuckers & & $\sqrt{ }$ & & \\
\hline 16. & Pissed off & & & $\sqrt{ }$ & \\
\hline 17. & Shitty & & & $\sqrt{ }$ & \\
\hline 18. & Hell & $\sqrt{ }$ & & & \\
\hline 19. & Dumbass & & $\sqrt{ }$ & & \\
\hline 20. & Bad-ass & & $\sqrt{ }$ & & \\
\hline 21. & Asses & & $\sqrt{ }$ & & \\
\hline 22. & Assholes & & $\sqrt{ }$ & & \\
\hline 23. & Asshole & & $\sqrt{ }$ & & \\
\hline 24. & Prick & & $\sqrt{ }$ & & \\
\hline 25. & Fucked up & & $\sqrt{ }$ & & \\
\hline 26. & Suck a dick & & $\sqrt{ }$ & & \\
\hline 27. & Kick-ass & & $\sqrt{ }$ & & \\
\hline \multirow{2}{*}{\multicolumn{2}{|c|}{$\begin{array}{c}\text { Total } \\
\text { Percentage (\%) }\end{array}$}} & 3 & 20 & 4 & 27 \\
\hline & & $11,1 \%$ & $74,1 \%$ & $\begin{array}{c}14,8 \\
\%\end{array}$ & $100 \%$ \\
\hline
\end{tabular}

Notes:

$\begin{array}{ll}\text { REG } & \text { : Religion } \\ \text { PRIV\&SEX } & \text { : Private Parts of the Body and Sexual Activity } \\ \text { LAV } & \text { : Lavatory }\end{array}$

There are three kinds of taboo words, such as religion, private parts of the body and sexual activity, and lavatory. All of them appear in the conversations spoken by the characters in the movie. From the table above, it can be noticed that the most dominant kind used by the characters is private parts of the body and sexual activity, which appears 20 times $(74,1 \%)$. Then, the second highest frequency is lavatory which appear 4 times $(14,8 \%)$. Finally, the least to occur is religion which appears 3 times $(11,1 \%)$. religion:
Captain Dickson: Goddamn! Infiltrate the dealers, find the supplier! (21 Jump Street, 16:49)

The literal meaning of the word damn in the example is 'condemn to hell (rare in literal sense; mainly used as swearword)', so in this case the word goddamn act as taboo word because in the context, it is not used in right place and right situation. The word goddamn in the sentence refers to taboo words kind religion In this case, Captain Dickson ordered Jenko and Schmidt to infiltrate the drug dealer and search for his supplier. Captain Dickson was annoyed at both Jenko and Schmidt because 
they never stopped asking and still did not understand the mission they were going to carry out even though he had explained it.

An example of taboo words kind private parts of the body and sexual activity:

Schmidt: Oh, fuck! No! No! I-I...no! No, I just...I mean, you probably going with someone. (21 Jump Street, 02:01)

The literal meaning of the word fuck in the example is 'have sex with' so in this case the word fuck act as taboo word because in the context, the meaning of this word is completely changed. The word fuck in the sentence refers to taboo words kind sexual activity. In this case, Schmidt wants to take Melodie to go to the prom but he is nervous and unsure if Melodie will agree. Schmidt is shock to see Melodie's reaction that she does not seem to want to go to prom with him, so he quickly explained that he was just asking.

lavatory:

An example of taboo words kind

Jenko: Not so Slim Shady? What's up? Holy shit! (21 Jump Street, 03:37)
The literal meaning of the word shit in example (1) is 'excrement; defecate' so in this case the word shit act as taboo word because in the context, the meaning of this word is completely changed. The word shit in the sentence refers to taboo words kind lavatory. In this case, Jenko was surprised to see Schmidt because he did not expect Schmidt is going the same campus with him. Jenko did not expect that in the end Schmidt can enter the police academy because during high school, Schmidt was fat and geeky.

The Functions of Taboo Words and the Reason of the Characters in 21 Jump Street Movie to Use Taboo Words

Taboo words can be function as an exclamation of annoyance, exclamation of surprise, surprised question, insult (noun), insult (imperative verb + object), insulting request to go away, expression of unconcern (= 'I don't care'), violent refusal/rejection/defiance, intensifying adjective/adverb (used to emphasize an emotion), and miscellaneous. There are some reasons underlying the use of taboo words. They are psychological condition, social class, and ethnic group.

Table 2

Frequency of Occurrence of the Functions of Taboo Words and the Reason of the Characters in 21 Jump Street Movie to Used Taboo Words

\begin{tabular}{|c|c|c|c|c|c|c|c|c|c|c|c|c|}
\hline \multirow{2}{*}{ No. } & \multirow{2}{*}{ Taboo } & \multicolumn{6}{|c|}{ Function } & \multirow{2}{*}{ Total } & \multicolumn{3}{|c|}{ Reason } & \multirow{2}{*}{ Total } \\
\hline & & INS & EXA & SUQ & EXS & EME & MIIS & & PSC & SOC & ETG & \\
\hline 1. & Goddamn & $\sqrt{ }$ & & & & $\sqrt{ }$ & & & $\sqrt{ }$ & & & \\
\hline 2. & Damn & $\sqrt{ }$ & & & $\sqrt{ }$ & & & & $\sqrt{1}$ & & & \\
\hline 3. & Fuck & $\sqrt{ }$ & $\sqrt{ }$ & $\sqrt{ }$ & $\sqrt{ }$ & $\sqrt{ }$ & & & $\sqrt{1}$ & & & \\
\hline 4. & Suck my dick & $\sqrt{ }$ & & & & & & & $\sqrt{1}$ & & & \\
\hline 5. & Motherfucker & $\sqrt{ }$ & & & $\sqrt{ }$ & $\sqrt{ }$ & & & $\sqrt{ }$ & & & \\
\hline 6. & Suck somebody's dick & $\sqrt{ }$ & & & & & & & $\sqrt{1}$ & & & \\
\hline 7. & Titties & $\sqrt{ }$ & & & & & & & $\sqrt{ }$ & & & \\
\hline 8. & Fucking & $\sqrt{ }$ & $\sqrt{ }$ & & $\sqrt{ }$ & $\sqrt{ }$ & $\sqrt{ }$ & & $\sqrt{ }$ & $\sqrt{ }$ & & \\
\hline 9. & Shit & $\sqrt{ }$ & $\sqrt{ }$ & & $\sqrt{ }$ & & $\sqrt{ }$ & & $\sqrt{1}$ & $\sqrt{ }$ & $\sqrt{ }$ & \\
\hline 10. & Balls & $\sqrt{1}$ & & & & & & & $\sqrt{1}$ & & & \\
\hline 11. & Ass & $\sqrt{1}$ & & & & & & & $\sqrt{1}$ & & $\sqrt{1}$ & \\
\hline 12. & Bullshit & $\sqrt{1}$ & $\sqrt{ }$ & & $\sqrt{ }$ & & & & $\sqrt{1}$ & & $\sqrt{ }$ & \\
\hline 13. & Bitches & $\sqrt{1}$ & $\sqrt{ }$ & & & & & & $\sqrt{1}$ & & $\sqrt{ }$ & \\
\hline 14. & Dick & $\sqrt{ }$ & $\sqrt{1}$ & & & & & & $\sqrt{1}$ & & & \\
\hline 15. & Motherfuckers & $\sqrt{ }$ & & & & & & & $\sqrt{ }$ & & $\sqrt{ }$ & \\
\hline 16. & Pissed off & $\sqrt{ }$ & & & & & & & $\sqrt{1}$ & & & \\
\hline 17. & Shitty & $\sqrt{1}$ & & & & & & & $\sqrt{1}$ & & & \\
\hline 18. & Hell & & $\sqrt{ }$ & $\sqrt{1}$ & & & & & $\sqrt{1}$ & & & \\
\hline 19. & Dumbass & & $\sqrt{ }$ & & & & & & $\sqrt{ }$ & & & \\
\hline 20. & Bad-ass & & & & & $\sqrt{ }$ & & & $\sqrt{1}$ & & & \\
\hline 21. & Asses & & & & & $\sqrt{1}$ & & & $\sqrt{1}$ & & & \\
\hline 22. & Assholes & & & & & $\sqrt{ }$ & & & $\sqrt{1}$ & & & \\
\hline 23. & Asshole & & & & & $\sqrt{ }$ & & & $\sqrt{ }$ & & & \\
\hline 24. & Prick & $\sqrt{1}$ & & & & & & & & $\sqrt{ }$ & & \\
\hline 25. & Fucked up & & & & & & $\sqrt{ }$ & & $\sqrt{1}$ & & & \\
\hline 26. & Suck a dick & $\sqrt{1}$ & & & & & & & & & $\sqrt{ }$ & \\
\hline 27. & Kick-ass & & & & & $\sqrt{1}$ & & & & $\sqrt{ }$ & & \\
\hline & Total & 19 & 8 & 2 & 6 & 9 & 3 & 47 & 24 & 4 & 6 & 34 \\
\hline & Percentage (\%) & $\begin{array}{c}40,4 \\
\%\end{array}$ & $17,0 \%$ & $4,3 \%$ & $12,8 \%$ & $19,1 \%$ & $6,4 \%$ & $100 \%$ & $\begin{array}{c}70,6 \\
\%\end{array}$ & $11,8 \%$ & $17,6 \%$ & $100 \%$ \\
\hline
\end{tabular}

\section{Notes:}

INS: Insult

EXA: Exclamation of Annoyance

SUQ: Surprised Question

EXS: Exclamation of Surprise

EME: Emphasize an Emotion

MIS: Miscellaneous
PSC: Psychological Condition

SOC: Social Class

ETG: Ethnic Group 
There are six function of taboo words found in the movie, such as insult, exclamation of annoyance, surprised question, exclamation of surprise, emphasize an emotion, and miscellaneous. However, each of them has a different frequency. From those functions, the highest frequency of the function of taboo words is insult which appears 19 times $(40,4 \%)$. The second is emphasize an emotion which appears 9 times $(19,1 \%)$. The third is exclamation of annoyance which appears 8 times $(17,0 \%)$. The fourth is exclamation of surprised which appears 6 times $(12,8 \%)$. The fifth is miscellaneous which appears 3 times $(6,4 \%)$ and the last position is surprised question which appears 2 times (4,3\%). Meanwhile, the reason of the characters in 21 Jump Street movie used taboo words are, psychological condition, social class, and ethnic group. From those reasons, the highest frequency of the reason of using taboo words is psychological condition which appears 24 times $(70,6 \%)$. The second is ethnic group which appears 6 times $(17,6 \%)$ and the last position is social class which appears 4 times $(11,8 \%)$. Further, the functions of taboo words and the reasons of the characters in 21 Jump Street movie to used taboo words will be discussed below.

An example of taboo word function to insult with psychological condition reason:

Captain Dickson: Goddamn! Infiltrate the dealers, find the supplier! (21 Jump Street, 16:49)

The literal meaning of the word damn in the example is 'condemn to hell (rare in literal sense; mainly used as swearword)', so in this case the word goddamn act as taboo word because in the context, it is not used in right place and right situation. The function of the word goddamn in the sentence is to insult. In this case, Captain Dickson ordered Jenko and Schmidt to infiltrate the drug dealer and search for his supplier. Psychological condition is the reason why Captain Dickson used the word goddamn. Captain Dickson was annoyed at both Jenko and Schmidt because they never stopped asking and still did not understand the mission they were going to carry out even though he had explained it.

An example of taboo words function as an exclamation of annoyance with psychological condition reason:

Juario: Hey, will you all shut the hell up! I'm trying to research. (21 Jump Street, 24:12)

The word hell in the example acts as taboo word because this word is not used in the right place and right situation. The function of the word hell in the sentence is as an exclamation of annoyance. In this case, Juario who was researching was disturbed by the conversation between Jenko and Eric Molson. Psychological condition is the reason why Juario used the word hell. Juario feel annoyed at Jenko because in addition to disturbing, Jenko also called him a nerd.

An example of taboo words function as surprised question with psychological condition reason:

Eric Molson: Hey, what the hell? Are you serious? (21 Jump Street, 24:29)

The word hell in the example acts as taboo word because this word is not used in the right place and right situation. The function of the word hell in the sentence is as a surprised question. In this case, Jenko punches Juario after Juario challenges Jenko for calling him a nerd. Psychological condition is the reason why Eric Molson used the word hell. Eric Molson who saw Jenko punching Juario was annoyed that in addition to mocking, Jenko also hit Juario.

An example of taboo words function as an exclamation of surprise with psychological condition reason:

Mr. Walters: You have exceptional muscle tone there, young man. When did you go through puberty? Like at seven or something? You look like you're in your midtwenties for crying out loud. McQuade, huh? Doug McQuade! I read your file. You gotta lot of something special going on there, young man. What the hell was that? God damn it, son! Don't ever raise your hand to me like that again! Alright? I consider that a threat! (21 Jump Street, 34:50)

The word damn in the example act as taboo word because this word is not used in the right place and right situation. The function of the word damn in the sentence is as an exclamation of surprise. In this case, Jenko and Schmidt who are confused because they never succeeded in vomiting the drugs they had consumed accidentally met Mr. Walters as they run in the corridor. Psychological condition is the reason why Mr. Walters used the word damn. Mr. Walter tells Jenko that he has a good muscle and looks like he is in his mid-20s. Mr. Walter also said that he saw Jenko's file and was amazed because he has a lot of talent. However, suddenly Schmidt raised his hand to Mr. Walter. Mr. Walter was shocked and 
annoyed. He considers Schmidt's action as a threat.

An example of taboo words function to emphasize an emotion with psychological condition reason:

Tom Hanson: Goddamn it! Tom Hanson, DEA. On your knees! (21 Jump Street, $1: 29: 57)$

The literal meaning of the word damn in the example is 'condemn to hell (rare in literal sense; mainly used as swearword)', so in this case the word goddamn act as taboo word because in the context, it is not used in right place and right situation. The function of the word goddamn in the sentence is to emphasize an emotion. In this case, Jenko said Domingo was not fair because they dropped guns for a good cause. Psychological condition is the reason why Tom Hanson used the word goddamn. After Schmidt calls Domingo a liar and cruel, Tom Hanson then reveals his true identity that he is also a cop.

An example of taboo words function to insult with social class reason:

Jenko: There's not a nice way to put it. You're a fucking nerd. And, you know, she's, I don't know, she's hot. Look at her. Look at her. Look at her! Look at her! (21 Jump Street, 02:11)

The word fucking in the example above refers to taboo words. In this case Jenko teases Scmidt that he does not deserve to take Melodie to the prom night because Schmidt is a nerd while Melodie is a sexy girl who must be paired with a handsome man. The word fucking is used by Jenko, because this word is a powerful word which can disturb people who hears it. Jenko wants to insult Schmidt. More over the social class is the reason that makes the character use the word fucking, for instance, when people is angry with something or somebody, they tend to use taboo words to express what they feel.

An example of taboo words function as miscellaneous with psychological condition reason:

Schmidt: He...honestly he did get away, and he threw me down pretty hard. I actually fucked up my elbow pretty bad. (21 Jump Street, 10.17)

The literal meaning of the word fuck in the example is 'have sex (with)' so in this case the word fucked up act as taboo word because in the context, the meaning of this word is completely changed. The function of the word fucked up in the sentence is miscellaneous. In this case, Jenko and Schmidt were at the police station to tell the chronological arrest of the criminals they had committed to Deputy Chief Hardy. Psychological condition is the reason why Schmidt used the word fucked up. Schmidt explained to Deputy Chief Hardy that he accidentally injured his arm when he chased one of the criminals at the time of the incident. Schmidt uses the word fucked up as a substitute for the word injure.

An example of taboo words function to insult with ethnic group reason:

Captain Dickson: Get your motherfuckin' ass up when I'm talkin'! You will be going undercover as high school students. You are here simply because you look young. You some Justin Bieber, Miley Cyrus lookin' motherfuckers. (21 Jump Street, 12:15)

The literal meaning of the word ass in the example is 'bottom; buttock; anus;' so in this case the word ass act as taboo words because in the context, the meaning of this word is completely changed. Both words functions are to insult. In this case, captain Dickson ordered his juniors to listen well as he spoke. Ethnic group is the reason why Captain Dickson used the word ass and motherfucker. Captain Dickson used the word motherfucker to call his juniors who would perform an undercover mission.

An example of taboo words function to emphasize an emotion with social class reason:

Jenko: One; don't try hard at anything. Okay? Two; make fun of people who do try. Three; be handsome. Four; if anyone steps you on the first day of school, you punch them directly in the face. Five; drive a kick-ass car. Shit. (21 Jump Street, 21:46)

The literal meaning of the word ass is 'bottom; buttock; anus;'. so in this case the word kick-ass act as taboo word because in the context, the meaning of this words is completely changed. The function of the word kick-ass in the sentence is to emphasize an emotion. In this case, Jenko who went to school with Schmidt began explaining how to be a cool student to Schmidt. Social class is the reason why Jenko used the word kick-ass. Jenko explained to Schmidt that one of the ways to make them a cool student is to have a cool car. Jenko disappointed and surprised because the car they will drive to school is an old fashioned car that is not cool.

An example of taboo words function as miscellaneous with ethnic group reason: 
Domingo: Go ahead. You won't find any shit! Are you guys even real cops? You look like the kids on Halloween. (21 Jump Street, 06.43)

The literal meaning of the word shit is 'excrement; defecate;' so in this case the word shit act as taboo word because in the context, the meaning of this word is completely changed. The function of the word shit in the sentence is miscellaneous. In this case, Jenko who feels if group $1 \%$ stores some drug intends to check their vehicle. However Domingo says that Jenko will not find anything on his vehicle. Ethnic group is the reason why Domingo used the word shit. Domingo belittles Jenko and Schmidt; he doubts they are a tough cop so Domingo believes Jenko and Schmidt will not find any evidence to hold his group.

\section{IV.CONCLUSION}

There are three kinds of taboo words, such as religion, private parts of the body and sexual activity, and lavatory. All of them appear in the conversations spoken by the characters in the movie. The most dominant kind used by the characters is private parts of the body and sexual activity, which appears 20 times $(74,1 \%)$. Then, the second highest frequency is lavatory which appear 4 times $(14,8 \%)$. Finally, the least to occur is religion which appears 3 times $(11,1 \%)$. There are six functions of taboo words found in the movie, such as insult, exclamation of annoyance, surprised question, exclamation of surprise, emphasize an emotion, and miscellaneous. However, each of them has a different frequency. From those functions, the highest frequency of the function of taboo is insult which appears 19 times $(40,4 \%)$. The second is emphasize an emotion which appears 9 times $(19,1 \%)$. The third is exclamation of annoyance which appears 8 times $(17,0 \%)$. The fourth is exclamation of surprised which appears 6 times $(12,8 \%)$. The fifth is miscellaneous which appears 3 times $(6,4 \%)$ and the last position is surprised question which appears 2 times $(4,3 \%)$. Meanwhile, the reason of the characters in 21 Jump Street movie used taboo words are, psychological condition, social class, and ethnic group. The characters used taboo words because some of them are from lower class and their psychological condition always change depend on the situation of consequences of speech act. From those reasons, the highest frequency of the reason of using taboo words is psychological condition which appears 24 times $(70,6 \%)$. The second is ethnic group which appears 6 times $(17,6 \%)$ and the last position is social class which appears 4 times $(11,8 \%)$.

\section{REFERENCE}

Aitchison, J. (1992). Teach Yourself Linguistics. London: Hodder \& Stoughton.

Allan, K., \& Burridge, K. (2006). Forbidden Words: Taboo and the Censoring of Language. Cambridge: Cambridge Up.

Burridge, K. (2014). Taboo Words. The Oxford Handbook of the Word.

Fairman, C. (2009). Fuck: Word Taboo and Protecting our First Amendment Liberties. Illinois: Sphinx Publishing.

Gao, C. (2013). A Sociolinguistic Study of English Taboo Language. Theory and Practice in Language Studies, 3(12), 2310-2314. https:// doi.org/10.4304/tpls.3.12.2310-2314

Gray, A. (n.d.). Swearing in English. Retrieved from http://www.andrewgray.com/essays/ swearing.htm

Jay, T. (2000). Why We Curse: A Neuro Psycho Social Theory of Speech. Massachusetts: John Benjamins Publishing Company.

Pratama, A. D. Y. (2016). The Functions Of Taboo Words And Their Translation In Subtitling: A Case Study In "The Help." RETORIKA: Jurnal Ilmu Bahasa, 2(2), 350-363.

Swan, M. (1995). Practical English Usage (Second). Oxford: Oxford University Press.

Trudgill, P. (2000). Sociolinguistics: An Introduction to Language and Society (Fourth Edi). London: Penguin group.

Wardhaugh, R. (2010). An Introduction to Sociolinguistics (Sixth). British: Wiley Blackwell. 